\title{
Marine spawning sites of perch Perca fluviatilis revealed by oviduct-inserted acoustic transmitters
}

\author{
Mikkel Skovrind ${ }^{1}$, Emil A. F. Christensen ${ }^{1, *}{ }^{,}$Henrik Carl $^{1}$, Lene Jacobsen ${ }^{2}$, \\ Peter R. Møller ${ }^{1}$
}

\begin{abstract}
${ }^{1}$ University of Copenhagen, Natural History Museum of Denmark, Universitetsparken 15, 2100 Copenhagen, Denmark ${ }^{2}$ DTU Aqua, Technical University of Denmark National Institute of Aquatic Resources, Section for Freshwater Fisheries Ecology, Vejlsøvej 39, 8600 Silkeborg, Denmark
\end{abstract}

\begin{abstract}
In the 1970s, a flood-protection system dramatically changed a large part of the coastal environment of Køge Bugt, a bay in the western Baltic Sea, from open coast to a brackish lagoon habitat. An anadromous stock of European perch Perca fluviatilis seems to have benefitted from this change, but details about their spawning behavior remain unknown. We used oviductinserted acoustic transmitters to reveal the pre-spawning behavior and spawning sites of this population. Thirteen female perch were caught in the lower stream basin of St. Vejle $\AA$, and were tagged with acoustic transmitters inserted through the oviduct. The fish were tracked from March 2 to May 24, 2012 with both passive and active telemetry systems. The pre-spawning behavior involved short trips between the stream and adjacent lagoons. Twelve of the 13 transmitters $(92 \%)$ were expulsed during spawning, providing for the first time a strong proof of concept of oviduct-inserted acoustic transmitters in brackish and marine fish spawning studies. The transmitter expulsions were validated using an egg map, which was based on visual observations of perch egg-strands, and 11 of the 12 expulsed transmitters (92\%) were located in areas with eggs. Many fish spawned in the brackish water with salinities up to 9.6 PSU. These salinities are higher than those previously observed for European perch spawning in the wild, and call for further investigations of salinity tolerance in perch eggs.
\end{abstract}

KEY WORDS: Acoustic telemetry $\cdot$ Oviduct $\cdot$ European perch $\cdot$ Salinity $\cdot$ Spawning $\cdot$ Brackish water

\section{INTRODUCTION}

An innovative telemetric approach has recently been developed to identify spawning sites of freshwater fishes. By inserting small radio transmitters through the oviduct into the ovary of pike Esox lucius and muskellunge Esox masquinongy, spawning sites were revealed when the transmitters were expulsed along with the eggs during spawning (Pierce et al. 2006, Rasmussen 2007). This approach is furthermore an integrated method allowing detection of pre-spawning behavior of individuals (Rasmussen 2007). Unfortunately, radio telemetry is unusable in marine environments, as radio waves are heavily absorbed by salt water (Webber 2009). Sound waves,

\footnotetext{
*Corresponding author. Email: mts447@alumni.ku.dk
}

however, are only absorbed to a limited extent in salt water and acoustic telemetry may therefore constitute a suitable alternative to radio telemetry when applying the oviduct-inserted transmitter approach to marine environments. A European perch Perca fluviatilis population that appeared to spawn in a local brackish lagoon area was deemed suitable for testing oviduct-inserted acoustic transmitters. The European perch is a small (up to $55 \mathrm{~cm}$ ) percid fish which is distributed over a large part of the Eurasian continent. Eggs are spawned around April as a coherent egg-strand (Thorpe 1977). The perch is typically classified as a freshwater fish in terms of spawning habitat, but several different spawning migration strategies have been reported for populations occur-

() The authors 2013. Open Access under Creative Commons by Attribution Licence. Use, distribution and reproduction are unrestricted. Authors and original publication must be credited. 
ring in brackish water. Some subpopulations show anadromous behavior and migrate to freshwater to spawn, while others stay and spawn in brackish water (Nesbø et al. 1998, Snickars et al. 2010, Tibblin et al. 2011). Access to habitats of low salinity has been considered crucial for successful reproduction for perch living at salinities higher than $7 \%$ (Klinkhardt \& Winkler 1989, Olsen 2002). The objective of this study was to evaluate whether the oviduct-inserted acoustic transmitter approach is useful for revealing pre-spawning behavior and locating marine spawning sites of this species.

\section{MATERIALS AND METHODS}

\section{Study area}

The study was carried out $15 \mathrm{~km}$ south of the Copenhagen city center in the lowest part of the highly regulated stream St. Vejle $\AA$, and the adjacent

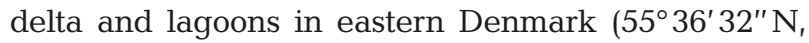
$12^{\circ} 22^{\prime} 44^{\prime \prime} \mathrm{E}$ ) (Fig. 1). The study area is located in the manmade Køge Bugt Strandpark, which is a $7 \mathrm{~km}$ long flood-protection system. This area was one of the biggest flood protection systems in Europe at the time of its completion in 1980 (Valgren \& Front 1986), and is now a popular recreational area.

The stream and the lagoons are connected to the delta by flood gates. The delta area consists of small islands and peninsulas, which form channels and narrow passages, and is connected to the marine bay, Køge Bugt, by a narrow entrance. The salinity of the bay measures approximately 10 PSU. Common reed Phragmites australis is the dominating aquatic vegetation along the stream, in the delta and in the lagoons. For the last 3 decades, local anglers have been aware of a large population of brackish-water European perch inhabiting the lowest part of the stream during winter (D. Rasmussen pers. comm.).

\section{Tagging}

Thirteen perch were caught by hook and line in the lower stream basin near receiver B (Fig. 1) during March 2012 (Table 1). During the day of capture, the fish were kept in a keep-net for up to $4 \mathrm{~h}$ before being transferred to a $60 \mathrm{l}$ tank to facilitate handling. After spending no more than 15 min in this tank, the fish were weighed and measured, and the transmitters were subsequently inserted through the oviduct into the ovary. The handling time above water of each fish was approximately 1 min and was performed without anesthesia. After tagging, the fish were immediately released back into the stream. The transmitters (Vemco, model v2-L7) were $20 \mathrm{~mm}$ long and $7 \mathrm{~mm}$ in diameter and transmitted at a frequency of $69 \mathrm{kHz}$. Transmissions were coded and sent at random intervals of between 40 and $80 \mathrm{~s}$ to prevent signal interference.

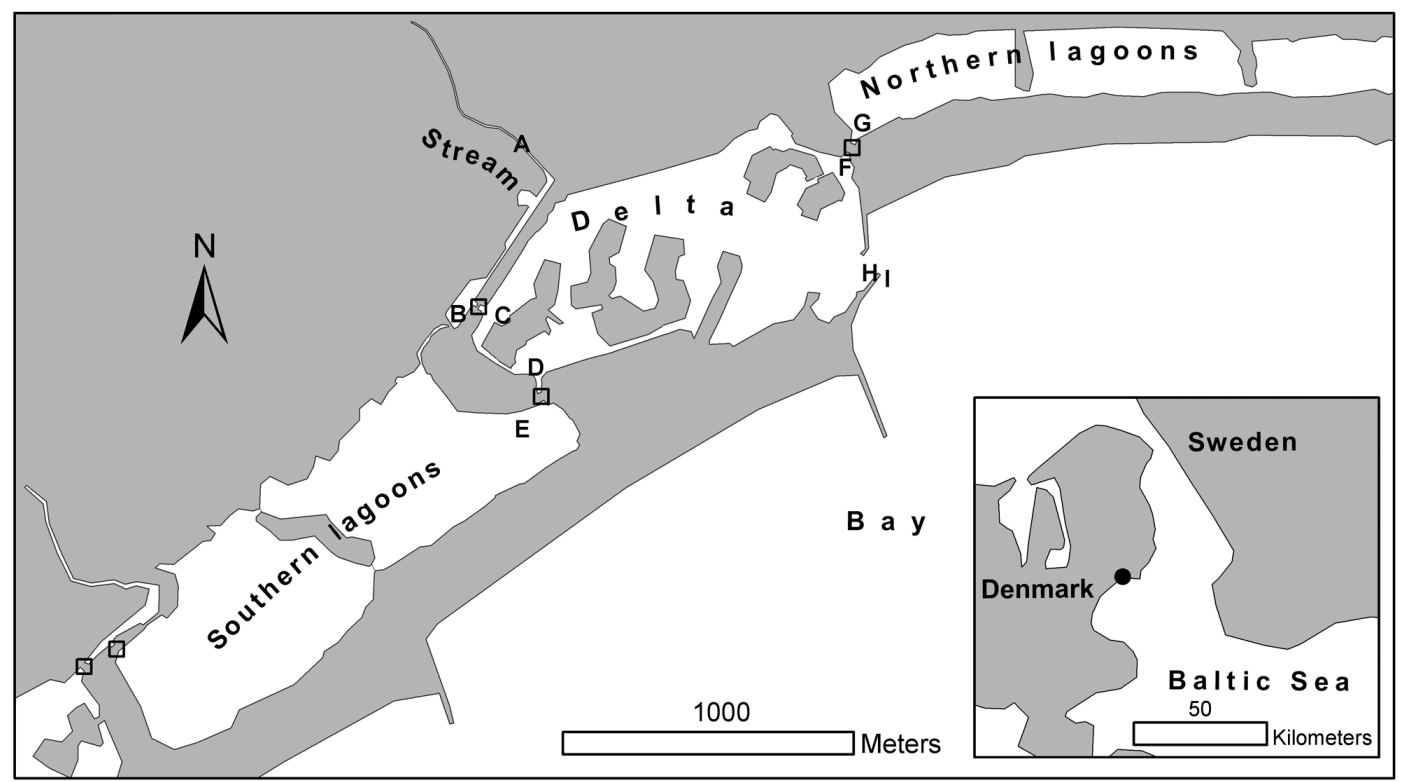

Fig. 1. The study area ( $\bullet$ on inset map) is located in the western Baltic Sea, eastern Denmark. It consists of 4 subareas: the stream, the delta and the northern and southern lagoons. Flood gates ( $\square$ ) form the transition between the subareas. The positions of the 9 stationary receivers used in the study are indicated with unique letters (A to I) 
Table 1. Perca fluviatilis. Data for each of the 13 tagged fish

\begin{tabular}{|lccc|}
\hline $\begin{array}{l}\text { Fish } \\
\text { no. }\end{array}$ & $\begin{array}{c}\text { Date of } \\
\text { tagging }\end{array}$ & $\begin{array}{c}\text { Weight } \\
(\mathrm{g})\end{array}$ & $\begin{array}{c}\text { Total } \\
\text { length }(\mathrm{cm})\end{array}$ \\
\hline 1 & $02 \mathrm{Mar}$ & 1180 & 43 \\
2 & $02 \mathrm{Mar}$ & 1320 & 43 \\
3 & $02 \mathrm{Mar}$ & 1140 & 40 \\
4 & $02 \mathrm{Mar}$ & 1200 & 43.5 \\
5 & $06 \mathrm{Mar}$ & 1330 & 42 \\
6 & $06 \mathrm{Mar}$ & 1540 & 44 \\
7 & $06 \mathrm{Mar}$ & 1180 & 40 \\
8 & $06 \mathrm{Mar}$ & 1060 & 39.5 \\
9 & $10 \mathrm{Mar}$ & 810 & 36 \\
10 & $10 \mathrm{Mar}$ & 1270 & 41.5 \\
11 & $10 \mathrm{Mar}$ & 1250 & 41 \\
12 & $10 \mathrm{Mar}$ & 850 & 36 \\
13 & $27 \mathrm{Mar}$ & 1500 & 45 \\
\hline
\end{tabular}

\section{Telemetry}

Nine stationary receivers/hydrophones (Vemco, model vr2) were deployed in the study area from March 2 to May 24, 2012 (Fig. 1). Receivers were placed on each side of the flood gates separating the delta from the stream and the nearby lagoons, so that movement of fish between subareas could be detected. Receivers were furthermore positioned $650 \mathrm{~m}$ upstream in St. Vejle $\AA$ and on both sides of the entrance piers (receivers $\mathrm{H}$ and I) connecting the delta to the bay, making it possible to detect whether a tagged fish left the study area. Range tests confirmed that receivers would detect any fish passing from one subarea to another. Data from the stationary receivers were used to describe pre-spawning behavior, in terms of movements between subareas, and to narrow down the search area for shed transmitters. Data were retrieved once a week from March 12 to May 24.

Manual tracking (Vemco VR-60) was done to determine the exact position of the transmitters and whether they were moving (i.e. still inside a fish), or motionless and therefore expulsed through the oviduct at the location of spawning. This was done from both land and boat by tracking from multiple positions twice a week from April 4 to May 15. The narrow passages and channels formed natural signal blockers allowing positioning accuracy to be in the range of 10 to $40 \mathrm{~m}$. In the more open areas with limited natural signal blocking, e.g. the southern lagoons, the location of a transmitter could only be determined within 75 to $125 \mathrm{~m}$. Multiple detections of a transmitter on subsequent dates in the same location were interpreted as a transmitter expulsed during spawning. Four such detections were obtained in most cases, but in 1 case, only 2 detections were achieved. In this case both detections were assumed to be post spawning due to the late date, and therefore accepted as a valid expulsion.

\section{Egg distribution map}

An egg distribution map showing the density of egg-strands in the stream, the delta and the associated lagoons was constructed from visual observations made from a boat using polaroid sunglasses. The amount of egg-strands was assessed on a 5-level scale ranging from 'no egg-strands' to 'many eggstrands' (see Fig. 2). Observations were noted on a map during field work throughout the study period. The egg distribution map enabled us to determine whether the expulsed transmitters were located in an area where egg-strands had been observed. For the purposes of our analyses, the spawning period was defined as the time between the first and the last day when egg-strands were observed.

\section{Salinity}

Temperature and conductivity were measured continuously throughout the study period with 2 loggers (Hobo, model U24-002). One was placed by receiver $\mathrm{B}$ in the stream where low salinities were expected and the other at receiver $\mathrm{F}$ in the outer delta where high salinities were expected. Salinities were also measured manually every 4 th day in the defined spawning period with a transportable refractometer (AB Aqua Medic). This was done near receiver D in the inner delta where large amounts of egg-strands were found. Salinities were calculated from the conductivity and temperature data using HOBOware Pro v.3.3.0.

In order to precisely determine the salinity around the eggs in the delta, a general linear model was built incorporating data from the 2 continuous loggers as well as the manual measurements. Pearson's correlation analyses were carried out (SAS v.9.2), and significant correlations were used to make the model. The yielded parameters were used to predict salinities, with the limitation that the salinity value could not exceed either one of the continuous measured values at a given time. Assuming 101 degree-days as suggested for $90 \%$ hatching by Craig (2000), the incubation period for the first observed egg-strands was extracted from the measured temperatures. The incubation salinity during this period could then be extracted from the salinity model. 


\section{RESULTS}

The validity of the transmitter expulsion rate was supported by the egg map. Eleven out of the 12 expulsed transmitters $(92 \%)$ were found at confirmed spawning sites (Fig. 2). Nine out of the 12 transmitters $(75 \%)$ were found in areas with an egg-strand density of level 2 or higher (Fig. 2).

\section{Telemetry}

The stationary receivers recorded 97489 detections in total. Detections were obtained by 7 of the 9 receivers. Receiver B detected 75995 signals, receiver D detected 21125 signals, receivers C, E, G and I recorded, in total, 369 signals, and receivers $\mathrm{A}$ and $\mathrm{F}$ detected no signals. During the study period, 9 fish (69\%) left the tagging site in the stream on 12 occasions. Two tagged fish left simultaneously once (within $2 \mathrm{~min}$ ), and all migrations between the stream and the delta took place between $08: 34 \mathrm{~h}$ and $13: 24 \mathrm{~h}$. Six of the fish that left the stream (67\%) returned to the stream after spending from $2 \mathrm{~min}$ to $3 \mathrm{~h}$ in the delta. The 4 fish that left the stream before March 15 all returned to the stream. After this date, 8 fish left the stream, but only $2(25 \%)$ returned. The remaining fish stayed in the delta or the southern lagoon until spawning.

Twelve out of 13 transmitters (92\%) were expulsed during the study period. The transmitter inside fish number 4 was assumed to be retained, since it continued to move long after the spawning period had ended. Seven of the 12 transmitters $(58 \%)$ were expulsed in the stream, $3(25 \%)$ in the delta and $2(17 \%)$ in the southern lagoons. The fish which expulsed their transmitters in the southern lagoons did so after small-scale migration from the stream to the lagoons via the delta.

The transmitters in the stream were found in the margins of the narrow, deeper part, immediately upstream of the pool created by the flood gate leading into the delta. The transmitters in the delta were all in the proximity of the flood gate leading into the southern lagoons close to receiver D. The transmitters located in the southern lagoons were far from each other and their exact positions were more difficult to determine. The stationary system detected movements of tagged fish between subareas at all times, except once. On this occasion the transmitter was last detected in the delta by receiver $C$, but was later expulsed in the stream without being detected by receiver $\mathrm{B}$.
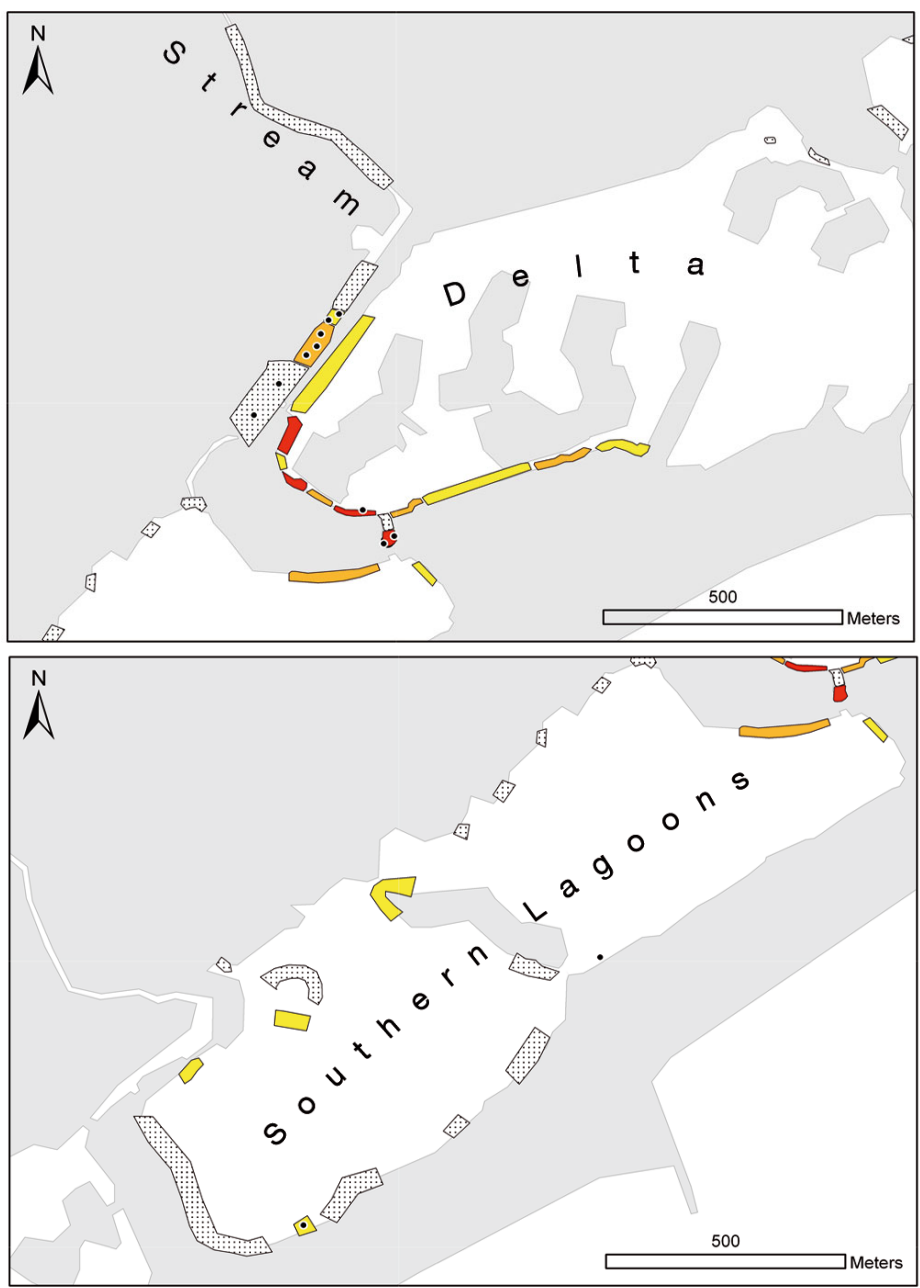

Fig. 2. Top: section of the egg-distribution map showing the expulsion sites of 10 transmitters $(\bullet)$. Bottom: section of the eggdistribution map showing the expulsion sites of 2 transmitters. No shading represents level 0 (no egg-strands), black-dotted shading represents level 1 (single egg-strands), yellow represents level 2 (few egg-strands), orange represents level 3 (more egg-strands) and red represents level 4 (many egg-strands)

\section{Egg distribution map}

The preferred spawning substrate was common reed Phragmites australis, and egg-strands were mainly observed in areas with water depths exceeding $0.5 \mathrm{~m}$. In the stream, the highest densities of eggstrands occurred in the margins of the narrow, deep part of the stream, just upstream of the lower stream basin (Fig. 2). The lower stream basin where the fish were caught for tagging held almost no egg-strands. In the calm western parts of the delta, egg-strands occurred abundantly, while no egg-strands were found in the deeper parts of the delta. The northern and southern lagoons also held egg-strands, but registrations were more scattered. 


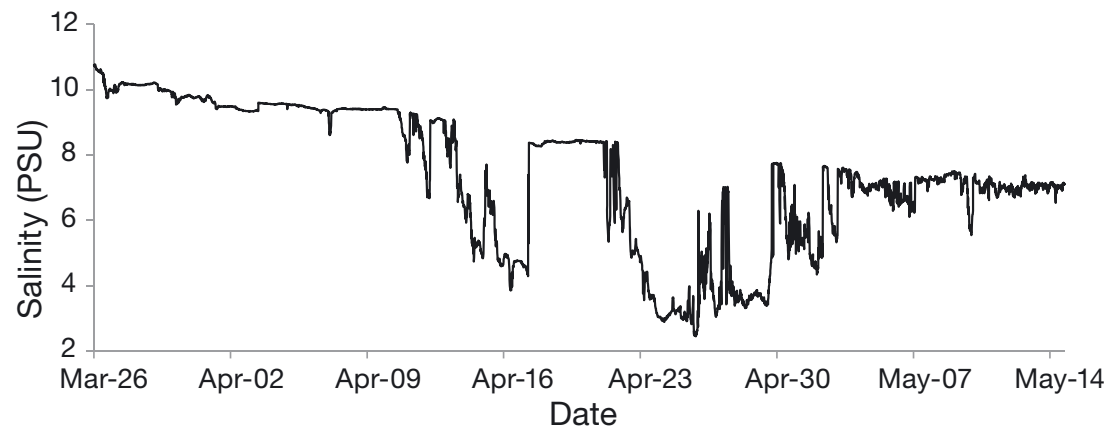

Fig. 3. Modeled salinity at an important spawning site in the delta close to receiver D

\section{Salinity}

The defined spawning period was April 2 to May 7. In this period, the model showed a salinity fluctuating between 2.4 and 9.6 PSU, with a mean \pm SD salinity of $7 \pm$ 2.2 PSU (Fig. 3). The extracted incubation salinity for the first observed egg-strands near receiver D fluctuated between 4.6 and 9.6 PSU. Salinity for this particular period was $8.7 \pm 1.3 \mathrm{PSU}$ (between April 2 and 16).

In the lower stream basin, salinity fluctuated between 0.4 and $8.8 \mathrm{PSU}$, with an average of $2.3 \pm 2 \mathrm{PSU}$ (Fig. 4). In the outer delta by receiver $F$, the salinity fluctuated between 6.4 and 12.3 PSU, with an average of $8.7 \pm 1.3 \mathrm{PSU}$. The manually measured salinities near receiver $\mathrm{D}$, at the site where large amounts of egg-strands were found, showed significant correlations with the continuous loggers in the delta $(\mathrm{p}=$ $0.03)$ and the stream $(p=0.05)$. Both of the continuous measurements were therefore included in the general linear model, which yielded the following:

$$
\begin{aligned}
E_{\mathrm{s}}= & -48.5 \times D_{\mathrm{s}}+6.02 \times S_{\mathrm{s}}+2.97 \times D_{\mathrm{s}}^{2} \\
& -0.65 \times D_{\mathrm{s}} \times S_{\mathrm{s}}+202.54
\end{aligned}
$$

where $E_{\mathrm{s}}$ is estimated salinity, $D_{\mathrm{s}}$ is delta salinity and $S_{\mathrm{s}}$ is stream salinity.

\section{DISCUSSION}

Telemetry

Our study provides a promising proof of concept for oviduct-inserted acoustic transmitters in revealing both the prespawning behavior and spawning sites of European perch. Such knowledge is important in the management of the species, both where it is a prized commercial or game fish (Europe) and where it is invasive (Australia). The method is also likely to be valuable for the management of many other marine and brackish-water fish. The combination of stationary and active telemetry was effective, as the stationary receivers narrowed down the areas in which it was necessary to search for expulsed transmitters. However, the exact positioning of the expulsed transmitters largely relied on the narrow passages and channels that divided most of the research area into smaller units. Exact positioning in more open areas would have required triangulation, as described by Arnold \& Dewar (2001).

The very high expulsion rate of transmitters during spawning $(92 \%)$ observed in the present study is higher than that of freshwater esocid species $(80 \%$ for pike and $60 \%$ for muskellunge) (Pierce et al. 2006). Pierce et al. (2006) suggested that the higher expulsion rate for pike than for muskellunge was due to the shorter spawning period and a less fractional egg-laying behavior of the pike. European perch spawn coherent egg-strands all at once. The high expulsion rate obtained for this species is therefore consistent with the hypothesis that transmitter expulsion rate during spawning is negatively affected by long spawning periods and fractional egg laying behavior. It seems likely that the spawning biology of
Fig. 4. Salinities in the stream and delta during the study period (March 2 to May 24)

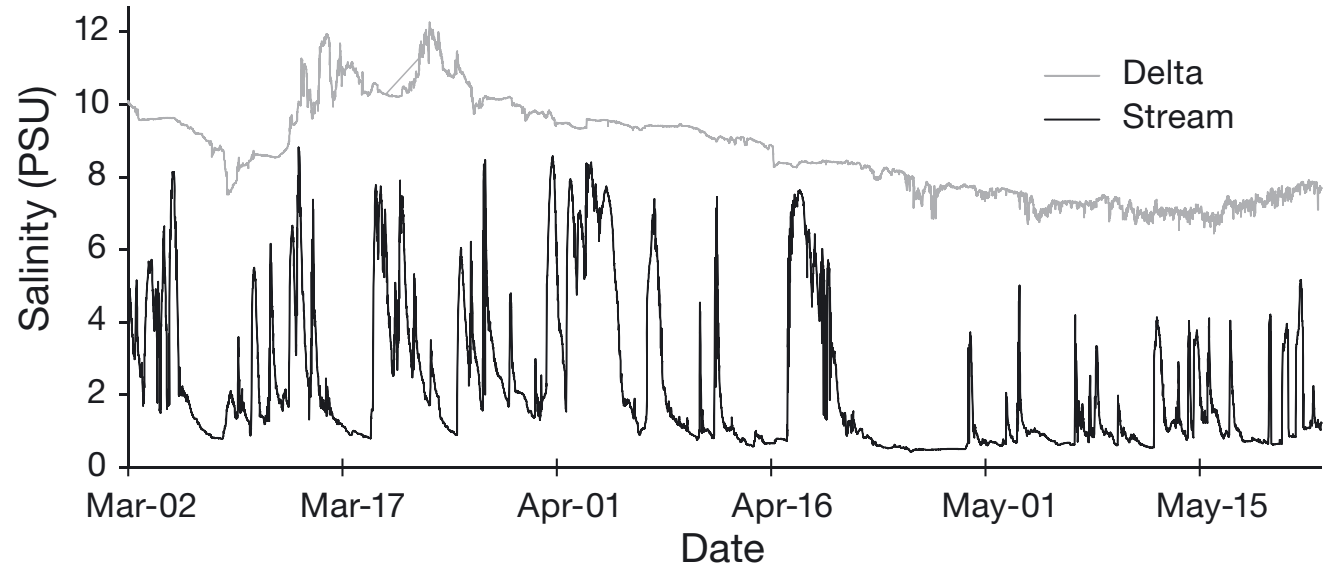


the perch demands a more robust oviduct and urogenital opening, which in turn facilitates the easier transmitter expulsion.

\section{Salinity}

The population showed no tendency to avoid the parts of the study area with high salinities when choosing spawning site. Snickars et al. (2010) presented a model that highlighted sheltered areas and suitable substrate as the most important factors when perch choose spawning sites. Their study did not, however, include salinity. The present results support the importance of substrate and shelter for perch spawning and indicate that salinity ranks lower than both of these factors, at least within a 0 to 10 PSU range.

The 9.6 PSU measured at the delta spawning site is higher than that previously observed for European perch spawning in situ (Snickars et al. 2010, Tibblin et al. 2011). As the salinity was high for an extended period, the first egg-strands observed were exposed to salinities up to 9.6 PSU (mean: 8.7 PSU) during development. Klinkhardt \& Winkler (1989), however, only describe egg hatching up to 7 PSU. The egg mortality in their study might have been increased by an interaction between salinity and temperature, as all eggs were incubated at 18 to $20^{\circ} \mathrm{C}$, a temperature range which is higher than optimal and ecologically relevant temperatures for perch eggs (Swift 1965). Our results therefore fall into an unknown area of perch egg salinity tolerance. Perch eggs either have a higher salinity tolerance in general than previously believed, or this western Baltic population has adapted to higher salinities. Such local adaptations have already been documented for juveniles and embryos of other freshwater fishes such as pike Esox lucius (Jørgensen et al. 2010) and ruffe Gymnocephalus cernua (Vetemaa \& Saat 1996), but not for perch.

\section{CONCLUSIONS}

This study validates the oviduct-inserted acoustic transmitter approach as a useful method for revealing pre-spawning behavior and spawning sites of perch in marine environments. By means of this method, perch were observed to spawn at a much higher salinity than what was previously thought possible. The method provides a unique way of getting insight into perch spawning biology, and could easily be applied in future studies of other brackishwater species and possibly even marine species.
Acknowledgements. Thanks to M. A. Krag, National History Museum of Denmark, for help in the field, to S. Christiansen and D. Rasmussen (Ishøj Sport Fishing Club) for valuable local observations and support, to M. Carøe (DTU Aqua) for introduction to acoustic equipment, to E. E. Sigsgaard, S. A. Christiansen and L. E. Christiansen for proof reading, to $\mathrm{M}$. Kaspersen (Danish Centre for Wild Salmon) for help and advice, to harbormasters for support, to the Danish AgriFish Agency and the Municipality of Ishøj for authorizations and to the Aage V. Jensen foundation and National History Museum of Denmark for financial support.

\section{LITERATURE CITED}

Arnold G, Dewar H (2001) Electronic tags in marine fisheries research: a 30-year perspective. In: Sibert J, Nielsen J (eds) Methods and technologies in fish biology and fisheries, Vol 1. Academic Press, Dordrecht, p 7-64

Craig JF (2000) Percid fishes: systematics, ecology and exploitation. Blackwell Science, Oxford

Jørgensen AT, Hansen BW, Vismann B, Jacobsen L, Skov C, Berg S, Bekkevold D (2010) High salinity tolerance in eggs and fry of a brackish Esox lucius population. Fish Manag Ecol 17:554-560

Klinkhardt M, Winkler HM (1989) Einfluß der Salinität auf die Befruchtungs- und Entwicklungsfähigkeit der Eier von vier Süßwasserfischarten Plötz (Rutilus rutilus), Barsch (Perca fluviatilis), Kaulbarsch (Gymnocephalus cernua) und Zander (Stizostedion lucioperca). Wiss Z Univ Rostock 38:23-30

Nesbø CL, Magnhagen, C, Jakobsen KS (1998) Genetic differentiation among stationary and anadromous perch (Perca fluviatilis) in the Baltic Sea. Hereditas 129:241-249

Olsen JS (2002) Growth, migration and reproduction in a population of brackishwater perch (Perca fluviatilis L.). MS thesis, University of Copenhagen

> Pierce RB, Younk JA, Tomcko CM (2006) Expulsion of miniature radio transmitters along with eggs of muskellunge and northern pike-a new method for locating critical spawning habitat. Environ Biol Fishes 79:99-109

Rasmussen PBIL (2007) Habitatvalg, aktivitet og gydning hos gedde (Esox lucius L.) i en lavvandet, kunstig sø. MSc thesis, University of Copenhagen

Snickars M, Sundblad G, Sandström A, Ljunggren L, Bergström U, Johansson G, Mattila J (2010) Habitat selectivity of substrate-spawning fish: modelling requirements for the Eurasian perch Perca fluviatilis. Mar Ecol Prog Ser 398:235-243

$>$ Swift DR (1965) Effect of temperature on mortality and rate of development of the eggs of the pike (Esox lucius L.) and the perch (Perca fluviatilis L.). Nature 206:528

Thorpe JE (1977) Morphology, physiology, behavior, and ecology of Perca fluviatilis and P. flavescens Mitchill. J Fish Res Board Can 34:1504-1514

Tibblin P, Koch-Schmidt P, Larsson P, Stenroth P (2012) Effects of salinity on growth and mortality of migratory and resident forms of Eurasian perch in the Baltic Sea. Ecol Freshwat Fish 21:200-206

Valgren E, Front PO (1986) Køge Bugt Strandpark. I/S Køge Bugt Strandpark, Ishøj

Vetemaa M, Saat T (1996) Effects of salinity on the development of fresh-water and brackish-water ruffe Gymnocephalus cernuus (L.) embryos. Ann Zool Fenn 33:687-691

Webber D (2009) VEMCO acoustic telemetry new user guide. AMIRIX Systems, Halifax

Submitted: February 7, 2013; Accepted: July 20, 2013

Proofs received from author(s): September 27, 2013 